\title{
Congruence in Knowledge and Knower Codes: The Challenge of Enabling Learner Autonomy in a Science Foundation Course
}

\section{Karen Ellery}

\section{Abstract}

Learning objectives, pedagogic activities and assessment practices indicate the knowledge, practices and dispositions that are valued in a curriculum. In Legitimation Code Theory (LCT), what is valued and legitimised in a social practice is referred to as the 'code' of that practice. Success in a formal higher education context is dependent upon students both recognising the code and realising it through production of appropriate texts. Using two codes identified in an earlier study as a framework, this empirical case study examines the way in which the curriculum in general, and assessment practices in particular, signal what is required in a higher education science foundation course. Curriculum congruence within each of the codes is examined using data from course document analysis and observations of pedagogic interactions. Results indicate good congruence in the science-related knowledge code that is associated with students becoming and being knowledgeable scientists, but less so in the academic practices-related knower code that is associated with students becoming and being autonomous learners. Challenges associated with enabling the development of practices as well as dispositions and behaviours associated with learner autonomy are discussed, with strategic use of assessment practices, reflective exercises and diagnostic approaches being proposed as a means of guiding student learning.

Keywords: curriculum congruence, Legitimation Code Theory, learner autonomy, science access 


\section{Introduction}

Success in formal higher education contexts is dependent upon students both recognising what is valued as well as realising this through producing the appropriate 'text' that is required by that context (Bernstein 2000). This 'text' may be as simple as participating actively in a tutorial setting or as complex as writing a well-argued essay based on multiple sources in an exam. Signalling to students what is required is based on a multifaceted set of processes that usually starts with articulation of aims and objectives of a course, these are supported through a range of learning activities, and culminate in, or are reinforced further by, a set of assessment practices. Biggs (2002) claims that student learning is enhanced if these components (learning objectives, learning activities and assessment practices) are well aligned. However, Biggs (ibid.) and others (Boud 1995; Gibbs 1999) also assert that whilst course aims and objecttives and learning activities obviously influence student engagement to some degree, students tend to pay close attention to assessment practices, particularly high-stakes ones, resulting in these practices being a primary driver of learning.

Expectations associated with assessment can be transmitted to students through three main practices: cognitive level of the task as well as provision and use of both evaluation criteria and feedback (Shalem \& Slonimsky 2010: 762). Each practice in turn has the potential to influence student learning. In terms of cognitive level, lower-order tasks requiring recall and basic comprehension are likely to encourage rote and surface understanding, whilst higherorder questions necessitating application, analysis, evaluation or creation have the potential to shift students towards developing deeper understanding (Biggs 2003). In terms of evaluation criteria, several authors show that making criteria transparent and explicit can lead students to both recognise and realise what is required in the assessment context (O'Donovan, Price \& Rust 2001; Price, Rust \& O’Donovan 2003; Rust, Price \& O’Donovan 2003). However, studies indicate that poor engagement with criteria or differential understanding of criteria (Rust, Price \& O'Donovan 2003; Woolf 2004) may result in poor text realisation. Likewise, the importance of feedback in terms of enabling access is emphasised repeatedly in educational research (see Hattie \& Timperley 2007 review). Developmental feedback with a formative function, as opposed to evaluative feedback with a summative function, is particularly useful in this regard (Price et al. 2010). However, again research shows that various considerations such as lack of student engagement (Duncan 2007; McCann \& 
Saunders 2009), poor guidance in use of feedback (Weaver 2006), inappropriate feedback (Carless 2006; Poulos \& Mahoney 2008) and poor quality in feedback (Higgins, Hartley \& Skelton 2002; Weaver 2006) may also hinder production of appropriate texts.

Collectively, the articulated objectives, learning activities and assessment practices indicate the knowledge, values and dispositions required by a curriculum. These have strong disciplinary or field links and can be conceptualised as the 'code' that underpins, and is being legitimised by, the curriculum. According to Legitimation Code Theory (LCT), the 'legitimation code' is thus the currency used or proposed by actors (in this case lecturers) to define the practice (Maton 2014:24). Whilst disciplines in the sciences tend to have a stronger focus on disciplinary knowledge, and are therefore usually considered to have 'knowledge' codes, disciplines in the humanities often place more value on student attributes and dispositions, signifying legitimation of a 'knower' code (Maton 2014:24). However, in a recent study on legitimation codes in a higher education science foundation course, it was clear that attaining access to the specialised science-related knowledge code required students to attain access to what was termed an academic practices ${ }^{1}$ related knower code through becoming and being particular kinds of science learners - which proved to be challenging for many (Ellery 2018). The aim of this follow-up paper is to investigate the ways in which these two codes are made visible through the curriculum components of learning objectives, learning activities and assessment practices in this science foundation course, and examine how well these components align in order to support student learning and enable access for success. This paper therefore draws conceptually on the notion of curriculum alignment or congruence as well as on knowledge, knowers and underpinning codes of LCT, which are outlined in the following section.

\section{Conceptual Framework \\ Curriculum Congruence}

Biggs (1996; 2003) developed the concept of constructive alignment to enable

${ }^{1}$ The term 'academic practices' is used in this study to invoke social practices underpinned by values, rather than the term 'study skills' which tends to engender the idea of neutral practices which can be learned generically. 
better coherence in curricula. The 'constructive' component relates to how students construct meaning, and the 'alignment' component relates to alignment of course outcomes, learning activities and assessment practices (Biggs 2003:27). Whilst the concept has been used widely in teaching and learning literature (see Kandlbinder \& Peseta 2009), there has been some criticism of its efficacy. In their critique, Jervis and Jervis (2005:9) point to a conflict in theoretical stance between the constructivist approach to student learning and what they term a behaviourist pedagogy as articulated in the learning outcomes that require students to 'enact verbs of understanding'. They also comment on the poor accommodation of broader transdisciplinary knowledge in learning outcomes of most curricula. Albeit from slightly different perspective, similar points are made by other authors when they speak of poor accommodation in the concept of students 'ways of thinking and practicing' (McCune \& Hounsell 2005) or of students' knower dispositions and values (Millar \& Bester 2008; Clarence 2016). Nonetheless, most authors recognise the value in Biggs' approach in terms of probing closely aspects of coherence in the curriculum. In this study I therefore draw instead on the notion of 'curriculum congruence', as proposed by McCune and Hounsell (2005), which obviates the invocation of any particular learning theory and also suggests less of a 'linear' approach to any curriculum. This study assumes that learning takes place in social ways through participation in a knowledge community with its dispositions and values, and instead of using outcomes as the driving process for congruence, as proposed by Biggs (2003), it instead uses the underpinning curriculum 'codes' from LCT.

\section{Legitimation Code Theory}

LCT is an analytical and conceptual framework that allows us to understand social practice (Maton 2014). It is based on the assumption that any practice is influenced by a number of underpinning principles that legitimate the practice. These principles are the legitimation codes, or 'rules of the game' of that practice as determined by the primary actors of the practice (Maton 2014). In this paper the science foundation curriculum (including pedagogy and assessment) is the practice and the lecturers are the primary actors.

LCT employs a number of dimensions to help unpack any practice, but this paper uses only that of Specialisation - which considers what is 'special' in a practice. It is based on the assumption that every social/educational 
practice is oriented towards something (knowledge) and by someone (knower) (Maton 2014:29). This allows for analytical distinction between epistemic relations (ER); between practices and their object (in other words, what can legitimately be claimed as knowledge) and social relations (SR) between practices and their subjects (in other words, who can claim to be a legitimate knower; ibid.). The epistemic and social relations in any practice can be weaker $(\mathrm{ER}-$ or $\mathrm{SR}-)$ or stronger $(\mathrm{ER}+$ or $\mathrm{SR}+)$, and therefore can be represented on a two-dimensional plane as indicated in Figure 1. By examining the epistemic and social relations in a practice, we can establish whether and to what extent such relations are legitimated and plot them on the plane (Maton 2014). For example, an educational practice such as a chemistry curriculum typically legitimates chemistry knowledge and practices (i.e. has stronger epistemic relations; ER+) and does not value the opinion or stance of the learner (i.e. has weaker social relations; $\mathrm{SR}-$ ) and would therefore be located in the upper left quadrant of Figure 1. Such a curriculum would have a knowledge code, which is considered relatively common code in science disciplines (see Chemwor 2017; Maton 2014; Howard \& Maton 2011). In contrast, whilst a drama curriculum may require an expressive, networked, collaborative knower (i.e. stronger legitimation of social relations; SR+), the craft knowledge of acting may be somewhat less important for success (i.e. has weaker epistemic relations; ER-). Such a curriculum would be located in a bottom right quadrant and have a knower code, which is a relatively common code in the humanities and social sciences (see Clarence 2014; Luckett \& Hunma 2014; Maton 2010). It has been argued that music curricula often legitimate strongly both musical knowledge (stronger epistemic relations; ER+) as well as having a musical 'feel' or disposition (stronger social relations; SR+) and would likely be placed in the upper right quadrant with an elite code (Lamont \& Maton 2008). It is quite difficult to imagine a higher education curriculum with a relativist code where neither knowledge nor knowers are legitimated (i.e. ER-/SR-).

Any educational practice will legitimate to some degree both epistemic and social relations (or knowledge and knowers) but it is the primary focus that gives rise to the code. Whatever code is legitimated, there needs to be coherence between curriculum, pedagogy and assessment, otherwise there may be a code clash. This may happen when curriculum or pedagogy can legitimate a particular code, but the assessment requires something different. For example, the code in a tutorial interaction that requires students to express their everyday understanding and opinion on why some plants grow well in dry 
conditions, would be different from an assessment task code that requires good botanic knowledge outlining specific adaptations.

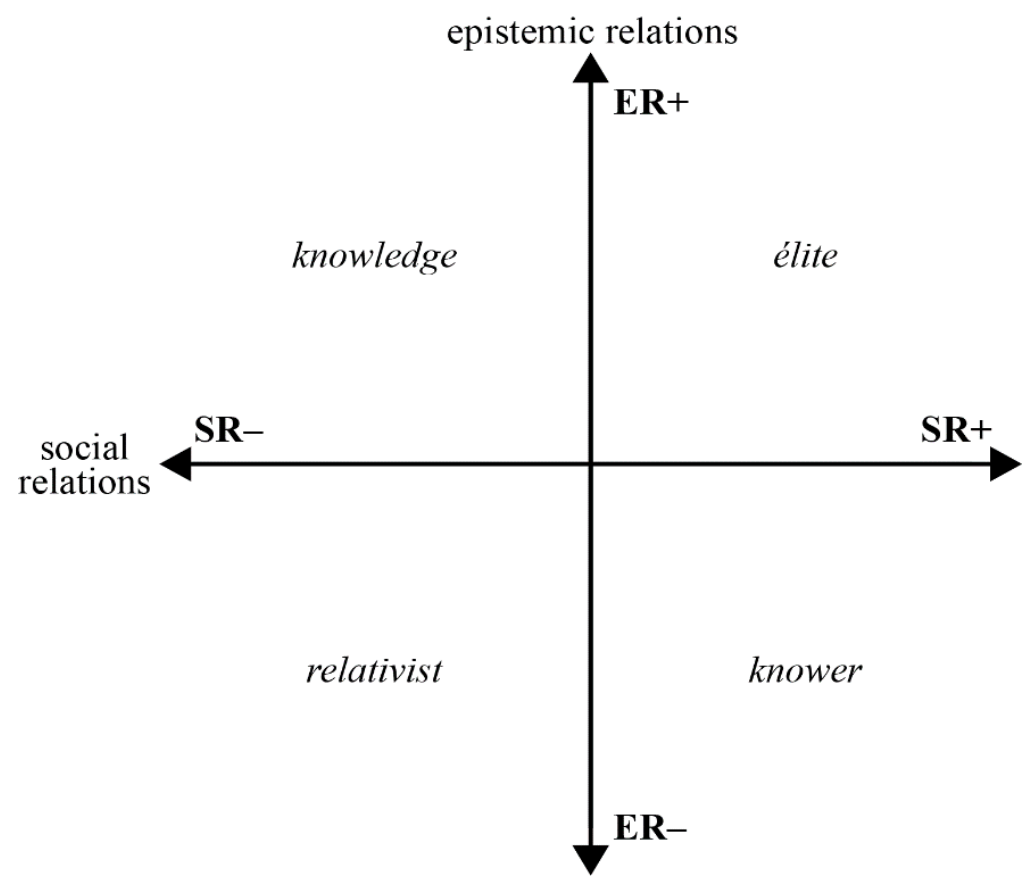

Figure 1: The specialisation plane: Four specialisation codes (knowledge, elite, knower and relativist) based on relative strengths of epistemic and social relations (source Maton 2016: 12).

An in-depth account of a multidisciplinary, science, higher education foundation course by Ellery (2018) showed that the curriculum is structured in such a way that two different codes are legitimated. The first is a sciencerelated knowledge code which is enacted by a strong focus on disciplinary knowledge and practices such as identifying rocks in geology or performing an accurate titration in chemistry (representing stronger epistemic relations; ER+) and little regard is given to student opinions or values (representing weaker 
social relations; $\mathrm{SR}-$ ). Also included in this code is scientific literacies knowledge and practices which focus on stronger epistemic relations linked to how science knowledge is constructed (observation, measurement, experimentation) and the basis on which knowledge claims can be made (use of empirical evidence, recognising uncertainty in science; which represent stronger epistemic relations; ER+). Whilst students are expected to develop dispositions and values associated with becoming and being scientific knowers (amongst other things, being rigorous, accurate, honest, objective, logical, analytical, critical), which would appear to represent stronger social relations, the assessment criteria are always linked directly to the epistemic relations, resulting in the social relations having a weaker categorisation (SR-). In LCT terms, stronger or weaker categorisations are founded on the basis upon which success is achieved in a practice rather than on the often more apparent focus (Maton 2014:31). For example, attributes of honesty and objectivity may be part of the focus when students conduct an experiment, but success is rather based on the scientific outcomes and the claims they make in their final report, resulting in an $\mathrm{ER}+/ \mathrm{SR}$ - categorisation.

The second is an academic practices-related knower code in which the focus is on students becoming autonomous and independent science learners. In this code knower attributes and dispositions are valued such that students are reflective and engaged in studies, work independently but seek assistance when required, are willing to engage, participate actively and develop metacognitive awareness, representing stronger social relations (SR+). The knowledge required by this code is a practical knowledge of a non-specialised nature, such as how to access information, take notes, and review lectures, and therefore represents weaker epistemic relations (ER-). The overall finding of the Ellery (2018) study is that student access to the science-related knowledge code is constrained by poor uptake of the academic practices-related knower code. This paper is an extension of the Ellery (2018) study in that it uses these codes as an overall framework in which to examine curriculum congruence in the same course, to better understand enabling and constraining conditions to student access for success.

\section{Study Context}

As part of a year-long science foundation programme, Introduction Science Concepts and Methods (ISCM) is a foundation course at a research-intensive 
university in South Africa that is designed for students whose social, economic and educational background may not have prepared them well for the rigours of higher education studies. The primary purpose of the course is to enable epistemological access such that students can be successful in their later mainstream science studies. As such, the focus of the course is threefold; developing conceptual understanding in four selected disciplines of physics, chemistry, earth sciences (geology) and life sciences (human kinetics and ergonomics - HKE), developing knowledge and dispositions related to becoming rigorous and critical scientists, and becoming and being autonomous learners able to develop depth understanding (Science Extended Studies Programme Review Report 2011). Specialists from their respective disciplines teach in formal lectures (two per week) and practical sessions (one per week). This disciplinary work, as well as aspects of learning in higher education, is supported by a 'scientific literacies' facilitator (myself, with a science background) and a 'language and literacies in the sciences' facilitator (a colleague with a language background) in less formal tutorial sessions (eight per week).

Assessment tasks are integral to the academic project in ISCM. The final November exam is the only assessment task in which there is no opportunity to learn from feedback and reflective processes. The four major assignments, which include an essay, a major laboratory report, an independent research project, and an abstract/summary assignment, all have draft phases that utilise appropriate criteria, in which there are structured opportunities for formative lecturer-, peer-, or self-evaluation. The six class tests, two examinations and four assignments are high-stakes and make up $80 \%$ of the final mark, and the other $20 \%$ comes from weekly low-stakes tasks completed in tutorial sessions.

\section{Methodology}

This is an empirical case study of a single science foundation course called Introduction to Science Concepts and Methods (ISCM). The primary source of data was course-related documents for a single year of teaching. These included semester outlines, course handouts (lecture, tutorial and practical sessions), resource materials (including chapters of books, journal and popular articles, YouTube videos), assessment tasks (tutorials, tests, exams and assignments), and written feedback on student work. These data enabled 
identification and classification of the curriculum into categories of learning objectives (overall course objectives and specific task objectives), pedagogic activities (relating to lectures, tutorials and practical sessions), and assessment practices (relating to assessment task questions, evaluative criteria used in assessment, and feedback given to students), as well as recognition of congruence between these components. This analysis was conducted for each of the two previously-mentioned legitimation codes: if the purpose of an activity related to enabling student becoming better learners, it was placed in the academic practices-related knower code category, and if the purpose was to develop science understanding, it was categorised as a science-related knowledge code activity.

These data were supported by observations of learning activities. In order to support my role as a scientific literacies facilitator, I attend all lectures and practical sessions and some tutorials taught by colleagues, in which I make informal observations on both course content and learning interactions. Whilst observations for this study were not specifically focussing on knowledge or knower codes at the time, they were sufficiently detailed to provide additional data for ISCM learning activities, according to the two codes, beyond that which existed in the documents.

Whilst capitalising on the advantages of being an insider researcher, such as having easy access to documents and interactions as well as legitimacy amongst participants (Chavez 2008), I was acutely aware of attendant challenges. To partly obviate the overlapping roles of teacher, colleague and researcher, all data was generated whilst I was on sabbatical leave. In an attempt to prevent the context from being normalised due to my familiarity with it (Chavez 2008), I tried to be deeply and critically reflective. Furthermore, to ensure reliability and validity I consulted regularly with colleagues on my data analysis and interpretation, as is suggested for qualitative research (Maxwell 2012).

\section{Results}

No attempt was made to quantify data. Generally, there was ample documentary and observational evidence for the science-related knowledge code in all six curriculum categories of course learning objective, task objectives, learning activities, assessment task questions, criteria and feedback 
(Table 1, column 1), as all lectures and practical sessions, and some tutorials, focus on this code. In the remaining tutorials the focus is on developing academic practices-related knowers. Documentary evidence indicates that support for the latter code occurs primarily in the first semester, with a reduced emphasis in the second semester.

In terms of the science-related knowledge code, broad disciplinary learning objectives, such as students being able to 'know, understand and apply scientific knowledge in different disciplines' are detailed in the course outline, and specific disciplinary practices and knowledge, such as balancing chemical equations, explaining the physical state of the earth's crust at different depths (geology), or determining the influence of gender on joint range of motion (HKE), are stated in learning activity documents and are addressed in class (Table 1). Likewise, broad scientific literacies learning objectives are articulated in the course outline and include knowing how scientific knowledge is constructed, communicating effectively, collecting and analysing data, and thinking critically in the sciences (Table 1). Specific objectives are also indicated for each scientific literacies learning activity. For example, an activity that focuses on aspects of scientific writing therefore articulates the objective clearly (students need to be able to recognise and describe the difference between every day and scientific writing) as well as has an appropriate associated task (students compare a popular and a scientific article on use of indigenous plants for medicinal purposes in order to identify characteristics of scientific text; Table 1).

In terms of assessment, both disciplinary and scientific literacies task questions are common in the ISCM curriculum (Table 1). These range from lower-order cognitive level questions (define, state, describe, list), but there are also mid-order questions (explain, identify, illustrate) as well as higher-order questions (argue, evaluate, analyse, predict, develop) in both low and highstakes assessment tasks. Likewise, in terms of criteria and feedback, both disciplinary and literacies aspects of the codes are well supported. Criteria are provided in advance for high-stakes assignments (essays and reports) and are explicitly addressed in the feedback of high-stakes tests, or in preparation for such tests. Whilst written criteria are not always provided for the numerous low-stakes tasks in the weekly tutorials, these are often verbalised during the learning activity. Feedback is comprehensive in this code, either individualised or in a group context, or in 'model' answers when specific (for example, calculated) answers are required. 
The Challenge of Enabling Learner Autonomy

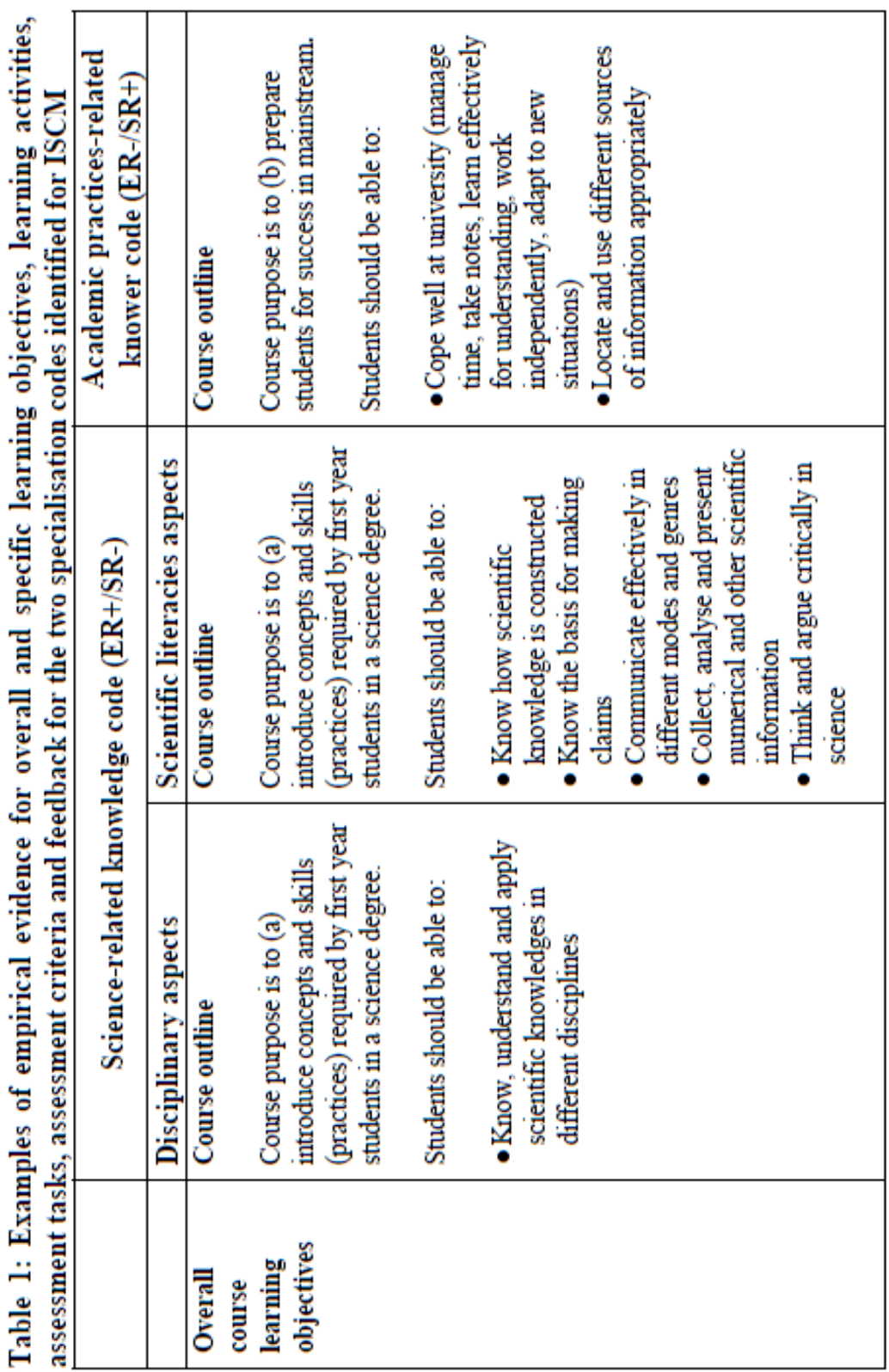


Karen Ellery

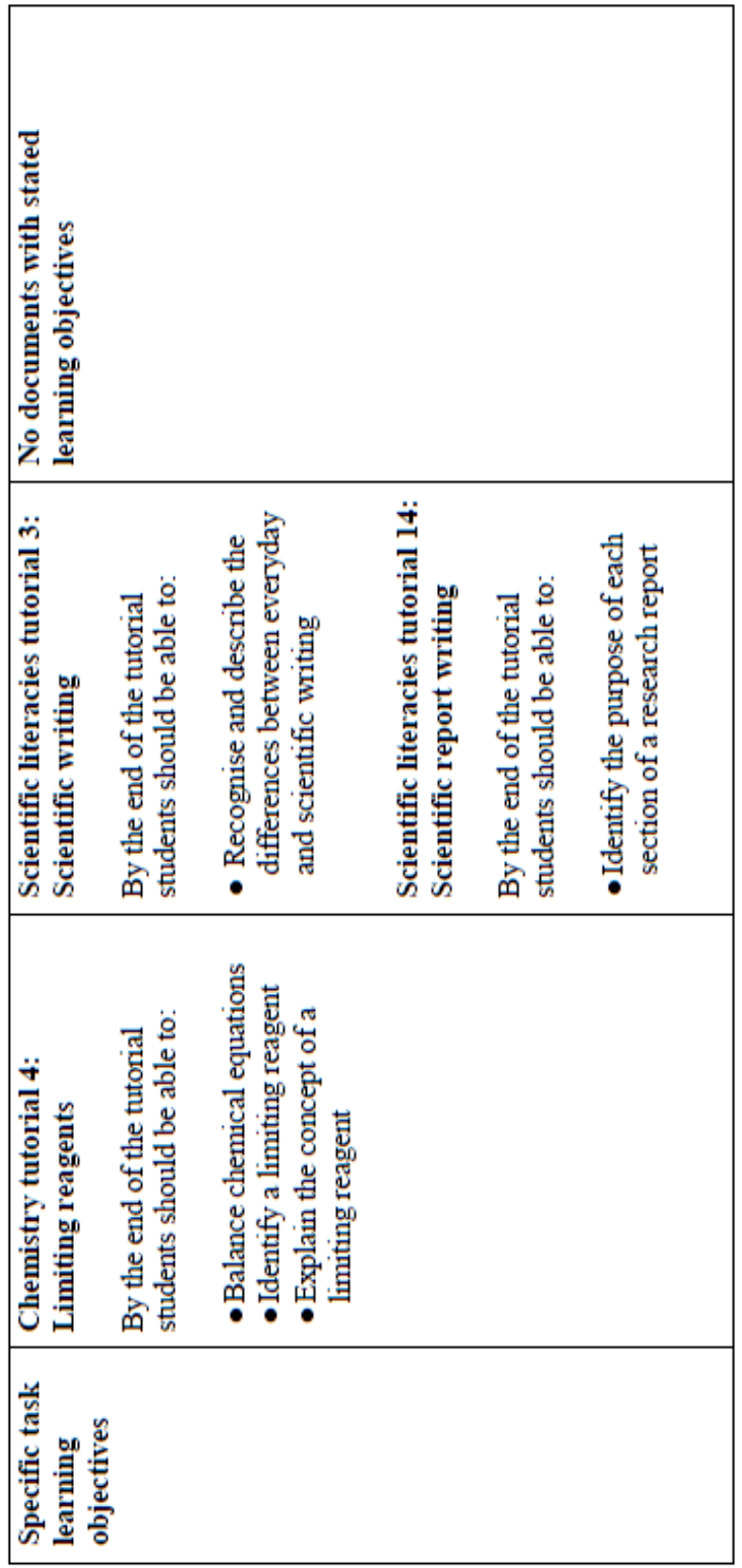




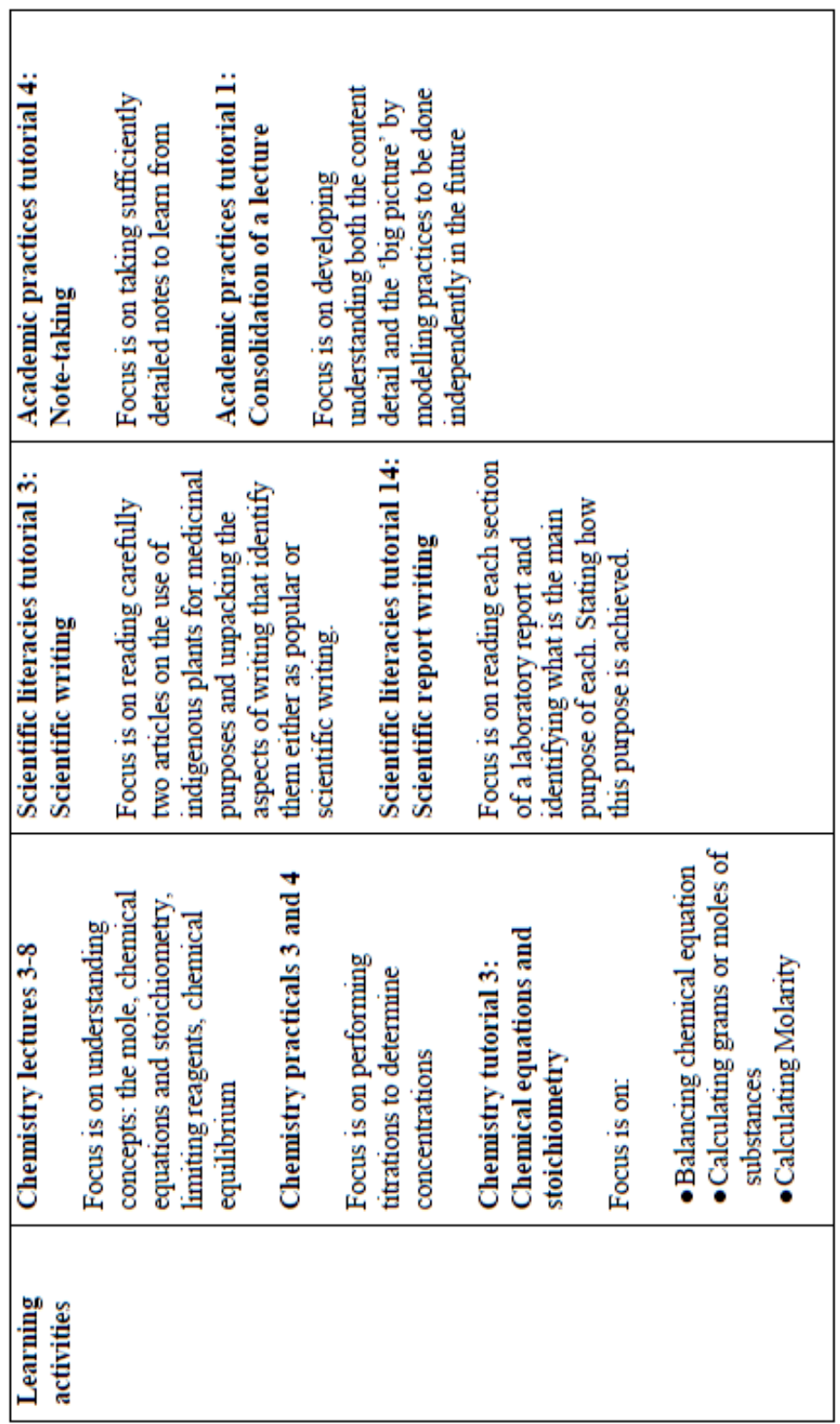


Karen Ellery

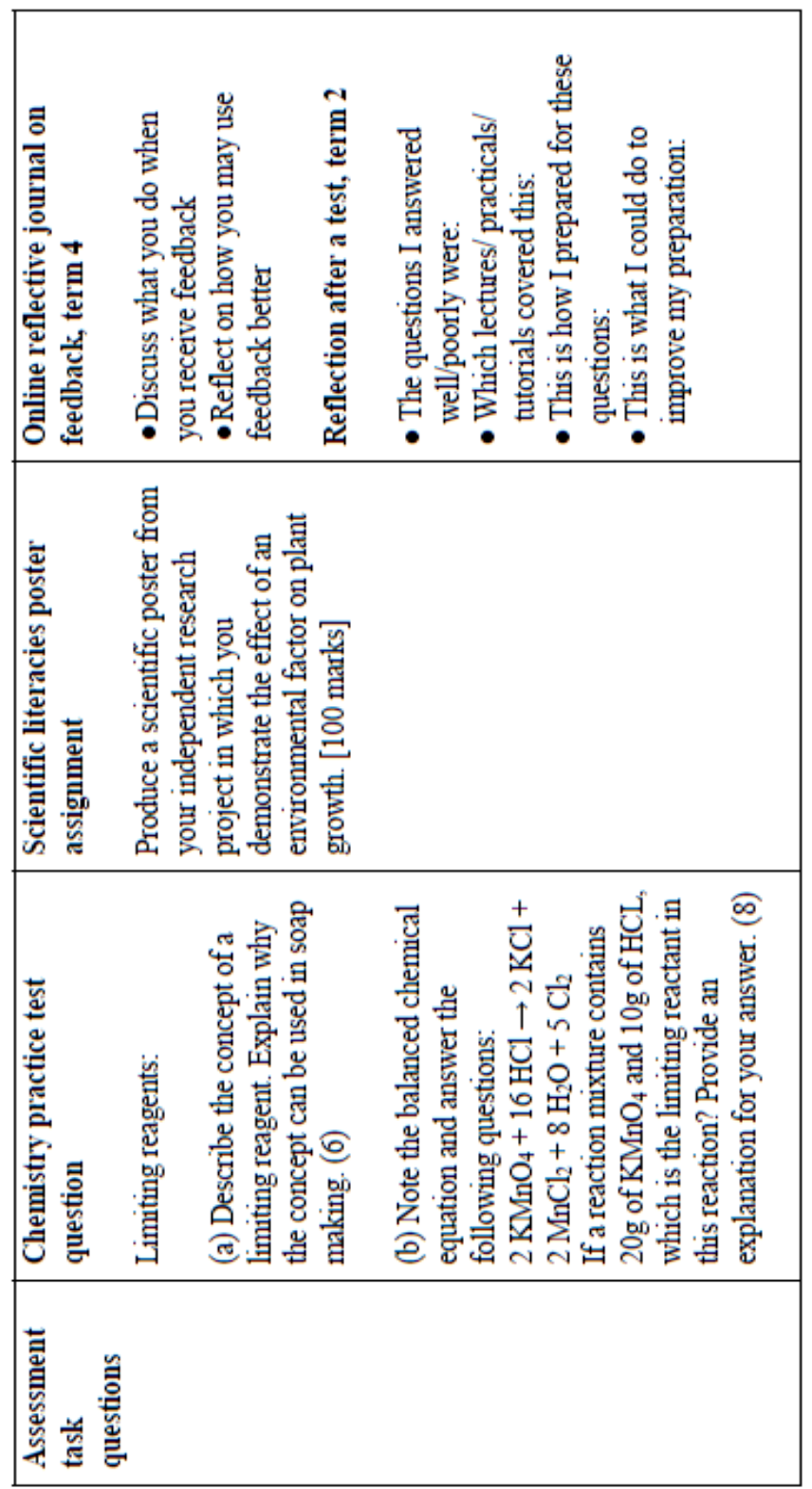




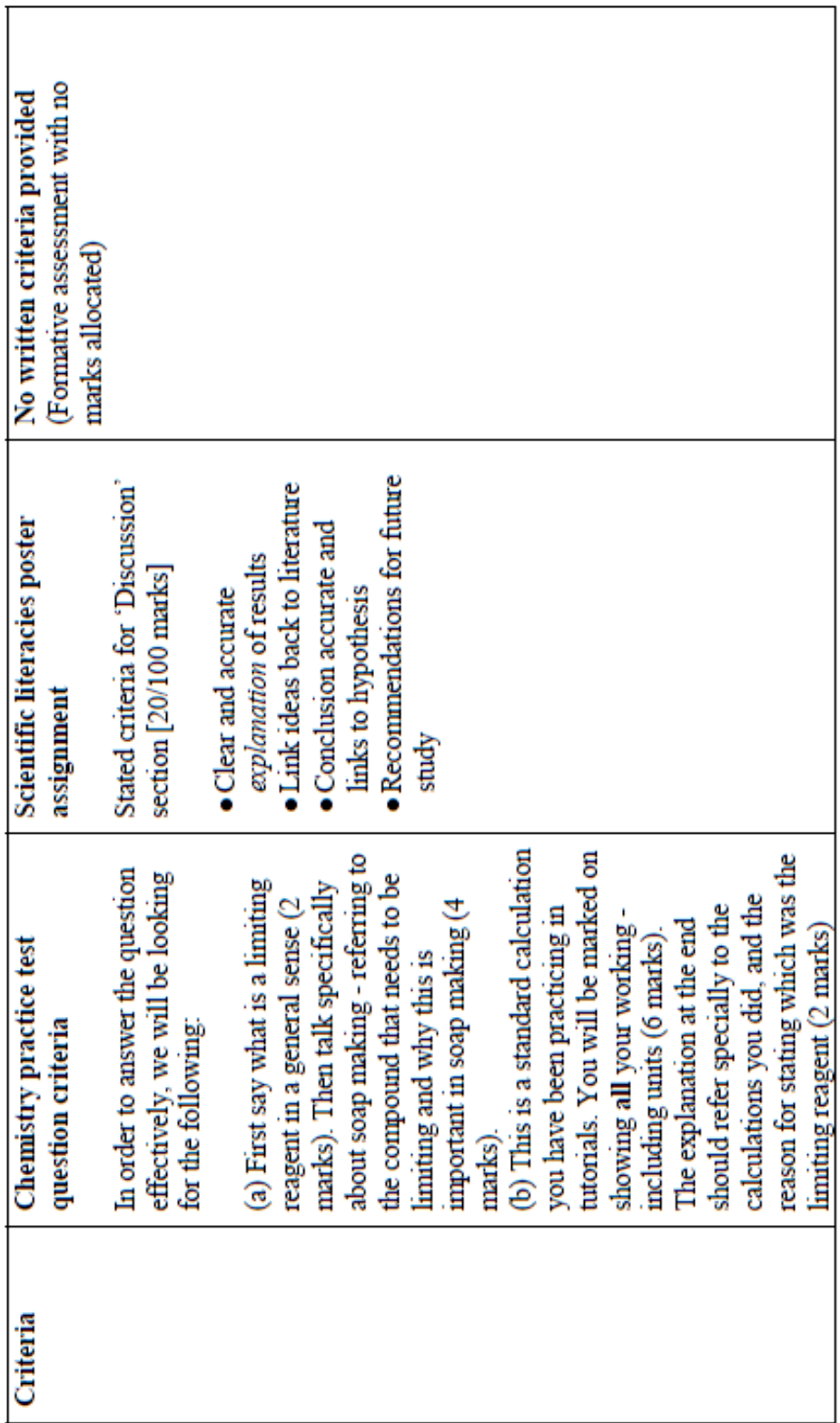


Karen Ellery

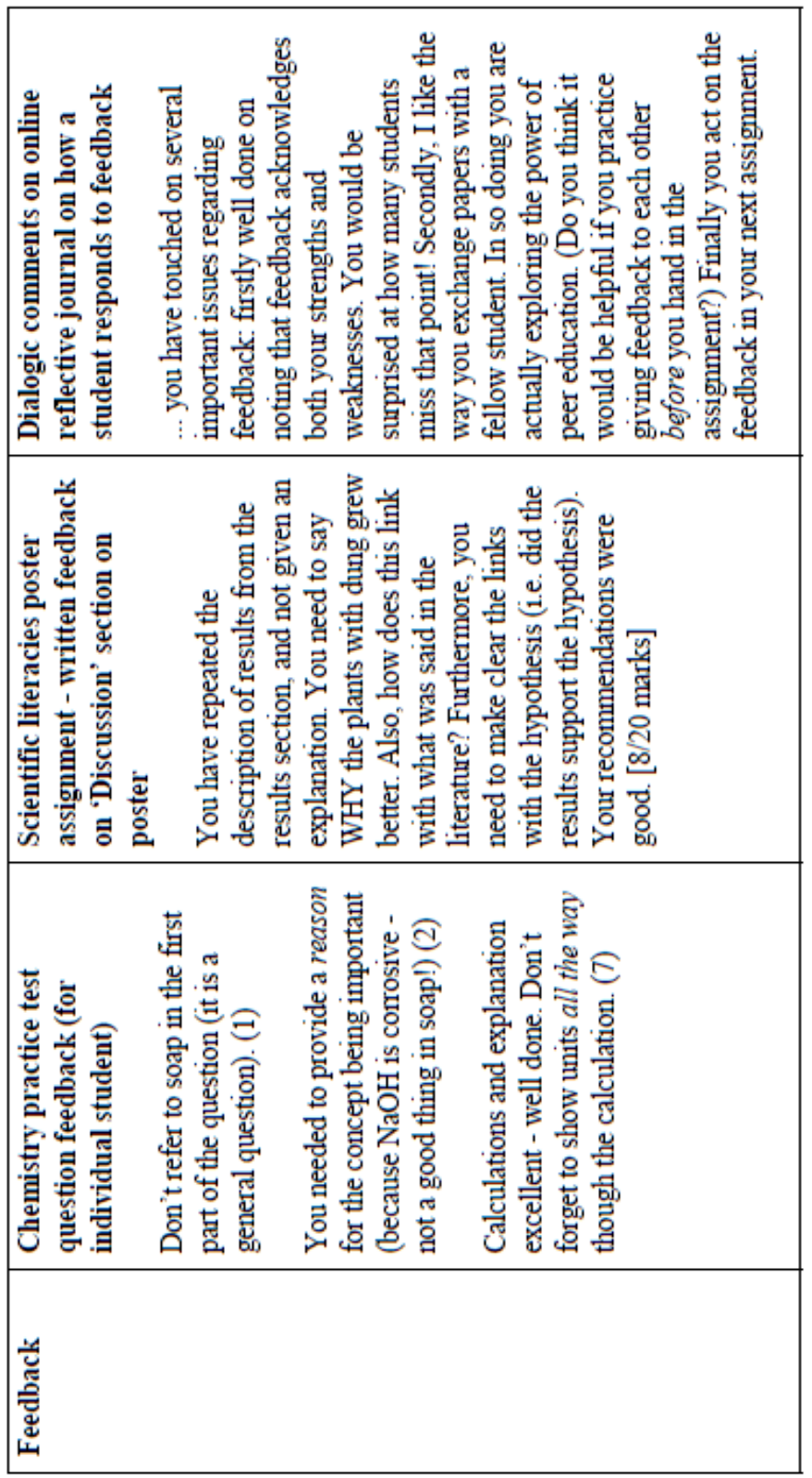


Whilst only a small sample of evidence has been presented in Table 1, the overriding trend in data for the science-related knowledge code was good congruence between the different curriculum components. However, in the academic practices-related code there were some obvious gaps in the data, indicating poorer congruence.

The academic practices-related knower code is supported at the broader level where the course learning objectives state that since ISCM is preparing students for success in mainstream they need to be able to manage time, takes notes, learn effectively and independently, locate information, and adapt to new situations (Table 1). These learning objectives are addressed actively in tutorials that focus on, amongst other things, note-taking, modelling lecture consolidation and review, reflecting on feedback to help improve learning. Observational evidence indicates that explicit verbal instruction and encouragement is given to students to engage in out-of-class activities such as preparatory reading, locating appropriate explanatory sources, developing deep understanding instead of rote learning, managing their time effectively, or bringing questions to class. However, the lack of accompanying handouts, with specified learning objectives for these activities, indicates a gap in congruence of this code (Table 1).

This incongruence is carried forward into the assessment practices for this code. In some tasks, such as enabling lecture consolidation and review in a follow-up tutorial, student's work is seldom assessed. When work is assessed, this is done formatively with no allocated marks (no-stakes assessment), nor are criteria provided (Table 1). The tasks that receive formative feedback are mainly those that prompt students to reflect on their progress, challenges they face, their approach to work at university, and how they respond to feedback, etc. The feedback students receive is of a conversational, affirmative and remindful nature, to encourage further appropriate engagement with the issues at hand.

\section{Discussion}

The ISCM foundation course aims to enable learning in higher education science. It legitimises two different codes: a science-related knowledge code that focuses on knowledge and practices of four distinct science disciplines, as well as of a more generalised scientific literacies, and an academic practicesrelated knower code that focuses on enabling effective learning practices for a 
higher education science context. This study indicates that congruence between stated learning objectives, focussed learning activities and assessment tasks, the latter of which exhibit a range of cognitive level questions in both highand low-stakes tasks with frequent use of evaluative criteria and formative feedback, provide support for the science-related knowledge code. However, the curriculum is less congruent in the academic practices-related knower code. Notable by their absence are learning activity handouts with stated specific learning objectives as well as criteria and marks associated with the assessment tasks. Furthermore, the main support for this code is in the first semester only. It is suggested that this curriculum incongruence, which gives rise to inappropriate signalling to students about what is valued in ISCM, could be contributing to the generally poor uptake of this code, as identified by Ellery (2018). The rest of this discussion focuses on challenges associated with supporting and enabling access to the academic practices-related knower code, which is about being a self-directed and independent learner.

ISCM, as a foundation course, is attempting to enable autonomy in learning such that students can be successful not only in ISCM but also later in their higher education mainstream studies where learning support is less likely to be available. The expectation in higher education is that students will engage in learner-directed strategies and practices that enable developing good understanding, being responsible for their own knowledge, studying independently, judging and monitoring their own progress, and responding actively and appropriately where needed. These expectations are very different from those at school where, particularly in the South African context, students are relatively passive with teachers directing many aspects of student learning and being ultimately responsible for students' knowledge and understanding (Pym \& Kapp 2013; CHE Report 2013). This makes the transition to higher education particularly challenging as many students simply continue to draw on learning practices utilised over 12 years of schooling. Unfortunately, this is compounded by the fact that most higher education contexts simply assume that students already know that their role is to work autonomously (Railton \& Watson 2005) and, consequently, there is little guidance in this regard. ISCM does not make this assumption, as evidenced by its overt articulation of learning outcomes and numerous associated learning activities that attempt to support better learning autonomy. However, the lack of congruence between these learning activities and follow-up assessment activities needs to be addressed. This assertion is based on the understanding that assessment 
practices are one of the most important aspects of the curriculum that influence student behaviours and can be used as a stimulus for learning (Boud 1995; Gibbs 1999; Biggs 2002). In this regard, the no-stakes assessment tasks of the academic practices-related knower code work, with no obvious direct benefit to students, are likely to engender much poorer engagement than the highstakes tasks associated with the science-related knowledge code.

Since academic practices-related activities such as consolidating a lecture or doing preparatory reading have the potential to improve students' performance in the science-related knowledge code in the long term, they tend to not be assessed directly in ISCM. Lemanski (2011:568) refers to this as 'non-assessed learning' as it is 'learning that will be indirectly rewarded in terminal summative assessment rather than directly awarded via continuous formative or summative assessment'. However, in Lemanski's study on exploring incentives for independent study, one of the primary reasons given by students for not completing weekly readings was the lack of assessment. Similarly, whilst ISCM students recognise and articulate well the indirect benefits of independence and self-responsibility, they find it hard to realise this in concrete action, which they too link mostly to lack of assessment incentives (Ellery 2016:188-190). It is therefore suggested here that strategic use of summative assessment tasks in ISCM may have the potential to incentivise and motivate for appropriate autonomous student engagement. It is acknowledged, however, that the relationship between assessment and autonomy in learning is not simple, particularly when taking into account both epistemic and social relations.

As outlined earlier, to become effective science learners students need to acquire not only certain practices and knowledge (representing weaker epistemic relations; ER-) but also certain knower dispositions (representing stronger social relations; SR+). Practices relating to learner autonomy, such as managing time, accessing information, preparing for all learning activities, taking notes, and consolidating and reviewing work, amongst others, are actively taught, modelled and scaffolded in ISCM classes, particularly in the first semester. Whilst work produced in these activities are currently not assessed, they certainly could be. Although initially such tasks may be completed for instrumental reasons of attaining marks, as suggested by Dobozy (2008) and Lemanski (2011), rather than for developing own understanding or self-responsibility, this approach of using marks as incentive may prove useful to initiate student engagement with appropriate learning practices. Additional 
motivation can be engendered through developing more direct links between the academic practices work and the disciplinary or scientific literacies work. For example, if one of the desired outcomes and means of attaining marks in practicals is being able to complete complex and time-consuming tasks efficiently and timeously, students will likely learn to prepare well for such practicals, particularly if the link between level of preparation and marks attained is made overt. Likewise, allowing students to utilise one-page summary consolidation notes during regular mini-tests can motivate for more consistent follow-up and engagement with disciplinary lecture content than may otherwise have been the case.

Whilst practices associated with autonomy in learning can be actively taught and relatively easily assessed, the required dispositions are less easily judged as they are not achievements per se, but rather are personal attributes that contribute towards achievement. Barnett (2009:433) defines dispositions are 'those tendencies of human beings to engage in some way with the world around them' and include a will to learn and engage, a preparedness to listen, explore and hold oneself out to new experiences, and a determination to keep going forward. He contrasts this with qualities, which are 'manifestations of dispositions in the world' and form part of an individual's character (Barnett 2009: 433) and can include courage, resilience, carefulness, integrity, selfdiscipline, restraint, respect for others, openness, generosity, and authenticity. However, in LCT, Barnett's dispositions and qualities appear to be encapsulated into what LCT refers to as 'knower dispositions'. For example, Barnett's quality of 'self-discipline' would simply be referred to as a knower disposition of 'being self-disciplined'. In this regard ISCM, through its academic practices-related knower work, is attempting to engender knower dispositions of being independent, self-disciplined, engaged, critical, curious, reflective, responsible and motivated.

Whilst some authors advocate assessing learning dispositions (Carr \& Claxton 2002; Deakin-Crick \& Yu 2008), Sadler (2002:49) makes the argument that such dispositions are 'context-dependent, situational, uncertain, and volatile', and suggests that any attempt at assessing learning dispositions in a generalised way is somewhat meaningless. He also makes the point that each individual will negotiate different paths and means of becoming a new kind of learner, depending on their own background context and the goals that motivate their current studies. In other words, students need to find for themselves the relevance of what they are doing, consider ways that work best 
for them to ensure success and, consequently, develop or draw on the dispositions necessary to achieve this. Whilst the argument being made here is that developing new knower dispositions is an individualised process that is unlikely to be driven by external forces such as assessment procedures, it is proposed that the curriculum can serve to make aware, guide and motivate for particular desired dispositions. In ISCM it is possible the use of reflective learning portfolios (Dyment \& O'Connell 2011) or diagnostic self-evaluation tools (Deakin-Crick \& Yu 2008) could be used in more structured ways to raise student awareness of their own learning dispositions and possibly promote behaviour change. However, it is acknowledged that many learning dispositions and behaviours are well-entrenched and changing them would be a long-term process that is unlikely to be achieved in a single, year-long foundation course.

\section{Conclusion}

Whilst this paper has focussed on a science foundation course in the South African context, I contend the findings have broader relevance. With current trends in massification and widening participation in the higher education sector as a whole, there is an increasing need to consider means of supporting student access and success. This applies particularly to students whose backgrounds have not necessarily prepared them well for success in the higher education context.

The main contribution of this paper is to use the well-developed concept of curriculum alignment or congruence in a new way using LCT, to reveal a social dimension to science learning that may not otherwise have emerged. It is argued that to signal effectively to students what is valued and expected, a curriculum needs close congruence between learning objectives, learning activities and assessment practices. However, as Clarence (2016:66) indicates, the alignment/congruence approach focuses largely on pedagogy and curriculum enactment and does not easily account for knowledge in the curriculum, nor the kinds of knowers students need to become. The complementary use in this paper of LCT, which recognises both knowledge and knowers, allowed for a more detailed and nuanced unpacking of a curriculum in two ways. Firstly, it provided an overall framework of two separate but distinct legitimation codes. From this it emerged that curriculum activities supporting the academic practices-related knower code were less 
congruent than the practices in the science-related knowledge code. Secondly, recognition of both epistemic and social relations within a curriculum provided a means to consider knowledge and practices, which are easily assessed, separately from knower dispositions and behaviours, which are not. This resulted in the fine-grained proposal that formative and summative assessment of both a direct and indirect nature could be used to support practices that enable independent learning, and that reflective or diagnostic approaches could be used to raise awareness and engender appropriate knower disposition development.

Whilst disciplinary knowledge tends to form the main focus of most science and other disciplinary higher education courses, becoming and being an independent learner is usually expected of students but is seldom explicitly articulated nor specifically supported, and therefore remains part of the 'hidden' curriculum. However, there is evidence that if students do not become the right kind of learners they cannot easily assess the powerful ${ }^{2}$ disciplinary knowledge (Case 2013; Wolff \& Hoffman 2014; Ellery 2018). This paper therefore adds its voice to the increased calls for pedagogies that make overt and support these expectations if higher education is to become accessible to an increasingly diverse study body.

\section{Acknowledgments}

Professor Chrissie Boughey is sincerely thanked for her contribution to this work. The study was supported by funding from the National Research Foundation (Grant no: 92685) and Rhodes University.

\section{References}

Barnett, R. 2009. Knowing and Becoming in the Higher Education Curriculum. Studies in Higher Education 34,4: 429 - 440.

https://doi.org/10.1080/03075070902771978

Bernstein, B. 2000. Pedagogy, Symbolic Control, and Identity: Theory, Research, Critique. Lanham: Rowman and Littlefield.

Biggs, J. 1996. Enhancing Teaching through Constructive Alignment. Higher Education 32,3: 347 - 364.

https://doi.org/10.1007/BF00138871

${ }^{2}$ Young and Muller (2013). 
Biggs, J. 2002. Aligning the Curriculum to Promote Good Learning. Paper presented at the Constructive Alignment in Action: Imaginative Curriculum Symposium, LTSN Generic Centre, November. Available at: http://www.qub.ac.uk.

(Accessed on 03 February 2018.)

Biggs, J. 2003. Teaching for Quality Learning at University. $2^{\text {nd }}$ Edition. Buckingham: SRHE and Open University Press.

Boud, D. 1995. Assessment and Learning: Contradictory or Complementary? In Knight, P. (ed.): Assessment for Learning in Higher Education. London: Kogan Page.

Carless, D. 2006. Differing Perceptions in the Feedback Process. Studies in Higher Education 31,2: 219 - 233.

https://doi.org/10.1080/03075070600572132

Carr, M. \& G. Claxton 2002. Tracking the Development of Learning Dispositions. Assessment in Education: Principles, Policy \& Practice 9,1: 9 - 37.

https://doi.org/10.1080/09695940220119148

Case, J.M. 2013. Researching Student Learning in Higher Education: A Social Realist Approach. London: Routledge.

Chavez, C. 2008. Conceptualizing from the Inside: Advantages, Complications, and Demands on Insider Positionality. The Qualitative Report 13,3: 474 - 494.

CHE (Council on Higher Education) Report 2013. A Proposal for Undergraduate Curriculum Reform in South Africa: The Case for a Flexible Curriculum Structure. Pretoria: CHE.

Chemwor, E.K. 2017. Knowledge and Knower Structures in Relation to Reproductive and Sexual Health in School Curricula of Kenya and South Africa. Unpublished Masters dissertation. Nelson Mandela University.

Clarence, S. 2014. Enabling Cumulative Knowledge-building through Teaching: A Legitimation Code Theory Analysis of Pedagogic Practice in Law and Political Science. Unpublished doctoral dissertation. Rhodes University, Grahamstown.

Clarence, S. 2016. Knowledge and Knowers in Teaching Learning: An Enhanced Approach to Curriculum Alignment. Journal of Education 66: $65-84$.

Deakin-Crick, R. \& G. Yu 2008. Assessing Learning Dispositions: Is the Effective Lifelong Learning Inventory Valid and Reliable as a Measure- 
ment Tool? Educational Research 50,4: 387 - 402.

https://doi.org/10.1080/00131880802499886

Dobozy, E. 2008. The Use and Usefulness of Non-assessed Online Learning:

Tracking Students' Behaviour on LAMS. In Cameron, L. \& J. Dalziel

(eds.): Proceedings of the 3rd International LAMS \& Learning Design

Conference 2008. Perspectives on Learning Design, 5 December 2008.

Sydney: LAMS Foundation. Available at:

http://lams2008sydney.lamsfoundation.org/papers.htm. (Accessed on 10

March 2018.)

Duncan, N. 2007. 'Feed-Forward': Improving Students' Use of Tutors'

Comments. Assessment \& Evaluation in Higher Education 32,3: 271 283. https://doi.org/10.1080/02602930600896498

Dyment, J.E. \& T.S. O'Connell 2011. Assessing the Quality of Reflection in

Student Journals: A Review of the Research. Teaching in Higher

Education 16,1: 81 - 97.

https://doi.org/10.1080/13562517.2010.507308

Ellery, K. 2016. Epistemological Access in a Science Foundation Course: A

Social Realist Perspective. Unpublished Doctoral Dissertation. Rhodes

University.

Ellery, K. 2017. A Code Theory Perspective on Science Access: Clashes and

Conflicts. South African Journal of Higher Education 31,3: 82 - 98.

https://doi.org/10.20853/31-3-1306

Ellery, K. (forthcoming). Widening Access in Science: Developing both

Knowledge and Knowers. In Maton, K. \& Y. Doran (eds.): Studying

Science. Forthcoming.

Gibbs, G. 1999. Using Assessment Strategically to Change the Way Students

Learn. In Brown, S. \& A. Glasner (eds.): Assessment Matters in Higher

Education. Buckingham: SRHE and Open University Press.

Hattie, J. \& H. Timperley 2007. The Power of Feedback. Review of

Educational Research 77,1: 81 - 112.

https://doi.org/10.3102/003465430298487

Higgins, R., P. Hartley \& A. Skelton 2002. The Conscientious Consumer:

Reconsidering the Role of Assessment Feedback in Student Learning.

Studies in Higher Education 27,1: 53 - 64.

https://doi.org/10.1080/03075070120099368

Howard, S. \& K. Maton 2011. Theorising Knowledge Practices: A Missing

Piece of the Educational Technology Puzzle. Research in Learning 
Technology 19,3: 191 - 206.

https://doi.org/10.1080/21567069.2011.624170

Jervis, L.M. \& L. Jervis 2005. What is the Constructivism in Constructive Alignment? Bioscience Education 6,1: 1 - 14.

https://doi.org/10.3108/beej.2005.06000006

Kandlbinder, P. \& T. Peseta 2009. Key Concepts in Postgraduate Certificates in Higher Education Teaching and Learning in Australasia and the United Kingdom. International Journal for Academic Development 14,1: 19 - 31. https://doi.org/10.1080/13601440802659247

Lamont, A. \& K. Maton 2008. Choosing Music: Exploratory Studies into the Low Uptake of Music GCSE. British Journal of Music Education 25,3: $267-282$.

https://doi.org/10.1017/S0265051708008103

Lemanski, C. 2011. Access and Assessment? Incentives for Independent Study. Assessment \& Evaluation in Higher Education 36,5: 565 - 581. https://doi.org/10.1080/02602930903541031

Luckett, K. \& A, Hunma 2014. Making Gazes Explicit: Facilitating Epistemic Access in the Humanities. Higher Education 67: 183 - 198.

https://doi.org/10.1007/s10734-013-9651-7

Maton, K. 2010. Progress and Canons in the Arts and Humanities: Knowers and Gazes. In Maton, K. \& R. Moore (eds.): Social Realism, Knowledge and the Sociology of Education. London: Continuum.

Maton, K. 2014. Knowledge and Knowers: Towards a Realist Sociology of Education. New York: Routledge.

https://doi.org/10.4324/9780203885734

Maton, K. 2016. Legitimation Code Theory: Building Knowledge about

Knowledge-building. In Maton, K., S. Hood \& S. Shay (eds.): Knowledge-building: Educational Studies in Legitimation Code Theory. London: Routledge.

Maxwell, J.A. 2012. Qualitative Research Design: An Interactive Approach. $3^{\text {rd }}$ Edition. London: Sage Publications.

McCann, L. \& G. Saunders 2009. Exploring Student Perceptions of Assessment Feedback. York: The Higher Education Academy, Social Policy and Social Work (SWAP Report). Available at:

http://eprints.lincoln.ac.uk/1832/1/SWAP_Assessment_Feedback.pdf (Accessed on 10 March 2018.)

McCune, V. \& D. Hounsell. 2005. The Development of Students' Ways of 
Thinking and Practising in Three Final-year Biology Courses. Higher Education 49: 255 - 289.

https://doi.org/10.1007/s10734-004-6666-0

Millar, B. \& M. Bester 2008. Moving beyond Constructive Alignment to Significant Learning. Paper presented at Higher Education Teaching \& Learning in Southern Africa (HELTASA) Conference, Grahamstown, November 30 - December 3. Available at:

http://www.academia.edu/9026156/Moving_beyond_constructive_align ment_to_significant_learning.

(Accessed on 10 March 2018.)

O'Donovan, B., M. Price \& C. Rust 2001. The Student Experience of Criterion-referenced Assessment through the Use of a Common Criteria Assessment Grid. Innovations in Education and Teaching International 38,1: $74-85$.

https://doi.org/10.1080/147032901300002873

Poulos, A., \& M.J. Mahoney 2008. Effectiveness of Feedback: The Students' Perspective. Assessment \& Evaluation in Higher Education 33,2: 143 154.

https://doi.org/10.1080/02602930601127869

Price, M., C. Rust \& B. O’Donovan 2003. Improving Students' Learning by Developing their Understanding of Assessment Criteria and Processes. Assessment \& Evaluation in Higher Education 28,2: 147 - 164.

https://doi.org/10.1080/02602930301671

Price, M., K. Handley, J. Millar \& B. O’Donovan 2010. Feedback: All that Effort, but What is the Effect? Assessment \& Evaluation in Higher Education 35,3: 277 - 289.

https://doi.org/10.1080/02602930903541007

Pym, J. \& R. Kapp. 2013. Harnessing Agency: Towards a Learning Model for Undergraduate Students. Studies in Higher Education 38,2: 272 - 284. https://doi.org/10.1080/03075079.2011.582096

Railton, D. \& P. Watson 2005. Teaching Autonomy: 'Reading Groups' and the Development of Autonomous Learning Practices. Active Learning in Higher Education 6,3: 182 - 193.

https://doi.org/10.1177/1469787405057665

Rust, C., M. Price \& B. O’Donovan. 2003. Improving Students' Learning by Developing their Understanding of Assessment Criteria and Processes. Assessment \& Evaluation in Higher Education 28,2: 147 - 164. 
Sadler, R.D. 2002. Learning Dispositions: Can we Really Assess them? Assessment in Education: Principles, Policy \& Practice 9,1: 45 - 51. https://doi.org/10.1080/09695940220119166

Science Extended Studies Programme Review Report 2011. Curriculum Review: Science Extended Studies Programme, Rhodes University. Unpublished report, Rhodes University, Grahamstown.

Shalem, Y. \& L. Slonimsky 2010. Seeing Epistemic Order: Construction and Transmission of Evaluative Criteria. British Journal of Sociology of Education 31,6: 755 - 778.

https://doi.org/10.1080/01425692.2010.515106

Weaver, M.R. 2006. Do Students Value Feedback? Student Perceptions of Tutors' Written Responses. Assessment \& Evaluation in Higher Education 31,3: 379 - 394.

https://doi.org/10.1080/02602930500353061

Wolff, K. \& F. Hoffman 2014. 'Knowledge and Knowers' in Engineering Assessment. Critical Studies in Teaching and Learning 2,1: 74 - 95.

Woolf, H. 2004. Assessment Criteria: Reflections on Current Practices. Assessment \& Evaluation in Higher Education 29,4: 479 - 493.

https://doi.org/10.1080/02602930310001689046

Young, M. \& J. Muller 2013. On the Powers of Powerful Knowledge. Review of Education 1,3: 229 - 250.

https://doi.org/10.1002/rev3.3017

Karen Ellery

Science Extended Studies Programme Centre for Higher Education Research, Teaching and Learning Rhodes University Grahamstown k.ellery@ru.ac.za 